OPEN ACCESS

Edited by:

Davide Cervia

Università degli Studi della Tuscia, Italy

Reviewed by:

Günther Zeck,

Natural and Medical Sciences

Institute, Germany

Daniel Llewellyn Rathbun,

Universität Tübingen, Germany

*Correspondence:

Steven F. Stasheff

steven.stasheff@nih.gov

Received: 27 June 2018

Accepted: 17 August 2018

Published: 10 September 2018

Citation:

Stasheff SF (2018) Clinical Impact

of Spontaneous Hyperactivity in Degenerating Retinas: Significance for Diagnosis, Symptoms, and Treatment.

Front. Cell. Neurosci. 12:298. doi: 10.3389/fncel.2018.00298

\section{Clinical Impact of Spontaneous Hyperactivity in Degenerating Retinas: Significance for Diagnosis, Symptoms, and Treatment}

\author{
Steven F. Stasheff ${ }^{1,2 *}$ \\ ${ }^{1}$ Center for Neuroscience and Behavioral Medicine, Gillbert Family Neurofibromatosis Institute, Children's National Health \\ System, Washington, DC, United States, ${ }^{2}$ Visual Neurophysiology, Neuro-ophthalmology and Pediatric Neurology, Retinal \\ Neurophysiology Section, National Eye Institute, Bethesda, MD, United States
}

Hereditary retinal degenerations result from varied pathophysiologic mechanisms, all ultimately characterized by photoreceptor dysfunction and death. Hence, much research on these diseases has concentrated on the outer retina. Over the past decade or so increasing attention has focused on concomitant changes in complex inner retinal neural circuits that process visual signals for transmission to the brain. One striking abnormality develops before the ultimately profound anatomic disruption of the inner retina. Highly elevated spontaneous activity was first demonstrated in central nervous system visual centers in vivo by Dräger and Hubel (1978), and subsequently has been confirmed in vitro, now in multiple animal models and by multiple investigators (see other contributions to this Research Topic). What evidence exists that this phenomenon occurs in human patients with retinal degeneration, and what is the ultimate effect of spontaneous hyperactivity in the output neurons, the retinal ganglion cells? Here I summarize abnormalities of visual perception among patients with retinal degeneration that may arise from hyperactivity. Next, I consider the disruption of neural encoding and anatomic connectivity that may result within the retina and in downstream visual centers of the brain. I then consider how specific characteristics of hyperactivity may distinguish various forms or stages of retinal degeneration, potentially helping in the near future to refine diagnosis and/or treatment choices for different patients. Finally, I review how consideration of these features may help optimize pharmacologic, gene, stem cell, prosthetic or other therapies to forestall visual loss or restore sight.

Keywords: retinal degeneration, hyperactivity, retinal ganglion cell (RGC), clinical impact, retinal remodeling, visual perception, neural encoding/decoding, visual restoration

\section{INNER RETINAL FUNCTION IN OUTER RETINAL DISEASE}

An ever-widening variety of genetic defects and biophysical mechanisms is recognized to cause progressive dysfunction and death of photoreceptors: hereditary retinal degenerations. Beyond this is an even broader array of neurologic and systemic disorders whose manifestations include retinal degeneration. 
Gradual loss of vision in these patients is, of course, expected as the primary light-sensing cells of the retina fail, and so scientific attention in these diseases long has focused on photoreceptors. Yet beyond these cells the neural circuits of the inner retina perform a tremendous amount of visual processing before information about the world we see is "compressed" and sent to visual centers in the brain. Arguably, the retina itself may be considered a structure of the central nervous system (CNS), a perspective that may be helpful to understand its normal function and deterioration with disease.

\section{POTENTIAL EFFECTS OF INNER RETINAL HYPERACTIVITY ON VISUAL PERCEPTION}

Up to $70 \%$ of patients with retinal degenerations report an impressive variety of visual symptoms beyond a simple scotoma ("blacking out" of a region of visual space). These range from photopsias and scintillations to complex formed hallucinations to imagined scenes or awakened visual memories (Heckenlively et al., 1988; Murtha and Stasheff, 2003; Bittner et al., 2009, 2011; Brown et al., 2015), reflecting the varied ways in which the retina's complex visual processing may be disrupted, not to mention the function of CNS visual pathways further downstream that form the conscious experience of the outside world, as such disease(s) progress (Ashtari et al., 2014).

The more complex of these abnormal visual perceptions may be considered a form of the Charles Bonnet syndrome originally described in 1760 in a patient with severe bilateral cataracts, but also reported for other forms of severe bilateral visual loss [e.g., age-related macular degeneration (AMD), diabetic retinopathy, or bilateral visual cortical injury] (Ffytche, 2005; Hedges, 2007; Cammaroto et al., 2008; Ffytche, 2009; Pang, 2016). In such cases, an analogy may be drawn to the "phantom limb" perception that may be caused by peripheral nervous system injury, and that appears to result at least partly from spontaneous hyperactivity of the injured neurons (Rachmachandran, 1992; Cammaroto et al., 2008; Schadlu et al., 2009; Pirowska et al., 2014; Luo and Anderson, 2016). Several articles in this Research Topic highlight the emergence of spontaneous hyperactivity among retinal ganglion cells (RGCs) in animal models of retinal degeneration, including the often oscillatory nature of such hyperactivity, and several different neural circuits in both inner and outer retina that can generate it (Barrett et al., 2015; Euler and Schubert, 2015; Ivanova et al., 2015b; Soto and Kerschensteiner, 2015; Trenholm and Awatramani, 2015; Goo et al., 2016; Tu et al., 2016; Zeck, 2016). Others have even drawn an analogy to epilepsy (Menzler and Zeck, 2011), although that disease category includes a plethora of individual diseases with widely variable manifestations and mechanisms (at least 30 broad but distinct types, according to the most recent international classification), most of which originate from CNS structures outside primary visual pathways (Fisher, 2017; Fisher et al., 2017).
How might this spontaneous hyperactivity among RGCs affect the vision of patients with retinal degeneration? It is easy to speculate that irregularly occurring bursts of such activity in RGCs, either individually or among groups of RGCs, would generate brief flashes of light, and that characteristics might vary substantially depending upon which functional type of RGC(s) were active at any given moment (Margolis and Detwiler, 2011; Menzler and Zeck, 2011; Yee et al., 2014). Alternatively, the excessive activity also may be viewed as "background noise" with the potential to interfere with the transmission of normal signals that create visual percepts when received and "decoded" by various visual center circuits in the brain. In its most simplistic conceptualization, the signal-to-noise ratio (SNR) may be decreased, simply in terms of the total rate of action potentials discharged by ganglion cells (Barrett et al., 2015; Ivanova et al., 2015b).

However, it now is widely accepted that a simple rate code cannot carry all the visual information conveyed by the retina to the brain (Baccus, 2007; Field and Chichilnisky, 2007; Schwartz and Berry, 2008; Jacobs et al., 2009; Koepsell et al., 2009; Sincich et al., 2009b; Tkacik et al., 2010; Xiao et al., 2013; Chaisanguanthum et al., 2014). A variety of more complex neural codes have been proposed to carry important visual information (Tkacik et al., 2010; Nirenberg and Pandarinath, 2012; Xiao et al., 2013; Chaisanguanthum et al., 2014; Marre et al., 2015; Rucci and Victor, 2015; Ioffe and Berry, 2017). These readily could incorporate mechanisms for complex and non-linear interactions between RGC spontaneous hyperactivity and "meaningful" activity that carries visual information. For example, vigorous light stimulation of normal retinas can provoke spontaneous RGC hyperactivity similar to that seen in retinal degenerations (Menzler et al., 2014). Conversely, electrical stimulation of degenerate retinas can reset the rhythm of spontaneous, oscillatory RGC hyperactivity (Ryu et al., 2010).

Classic Shannon information theory and variants of it have been employed to estimate the proportion of visual information that may be conveyed by some of these coding strategies (Shannon, 1948; Field and Chichilnisky, 2007; Sincich et al., 2009a; Wu and Srivastava, 2011). These theories also might be used to estimate the visual information lost due to hyperactivity disrupting the spatiotemporal structure of RGC spike trains in retinal degenerations. Alternatively, under certain conditions such as low contrast, visual noise may actually enhance visual perception: a principle known as stochastic resonance (Patel and Kosko, 2005; Kim et al., 2006; Funke et al., 2007; Trevino et al., 2016; van der Groen and Wenderoth, 2016). Too much, too little, or different types of noise, on the other hand, make images more difficult to perceive. In other animal models, RGC hyperactivity has been shown to disrupt the responses of central visual system neurons to light stimulation (Soto et al., 2012; Ivanova et al., 2015a; Soto and Kerschensteiner, 2015; Crair and Mason, 2016; Wang et al., 2016).

Just how such findings in animal models of retinal degeneration will translate to human visual perception in these diseases remains unclear. One framework for understanding how the central visual system may interpret or respond to abnormally elevated background RGC activity was developed initially to 
help understand amblyopia, and more recently also was applied successfully to patients with retinal degenerations: the concept of intrinsic equivalent noise (Pelli et al., 2004; McAnany et al., 2013). Patients are presented with standardized midrange contrast images to measure visual acuity with or without added background luminance "white noise." The difference in a patient's quantitative visual acuity measured in the presence vs. absence of this additional stimulus "noise" can be used to calculate the "efficiency" and "equivalent noise" of their visual perception. Thus, patients with various forms of hereditary retinal degeneration perform on such tests as if they perceive beyond the extrinsic visual stimulus - additional background noise intrinsic to the central visual system, noise that control subjects do not perceive (McAnany et al., 2013).

Aside from informing our understanding of how RGC hyperactivity may directly affect the visual perception of patients with retinal degenerations, these relatively simple methods might also prove useful as tools for clinical screening of patients with retinal degenerations, perhaps to detect more subtle deterioration of vision at earlier stages of disease progression. In turn, this might enable earlier, more effective treatments, and/or identify optimal treatment candidates.

The precise nature of RGC hyperactivity may vary with the specific form of retinal degeneration. For example, Goo et al. (2011a,b, 2016) have demonstrated subtle differences in the dominant frequency of oscillation in spontaneous activity between the $r d 1$ and $r d 10$ mouse models of retinitis pigmentosa, and at different developmental stages of $r d 10$ degeneration. Our own studies have demonstrated differences in the power spectrum density distribution of this activity between mouse models of two common forms of Leber's congenital amaurosis (LCA), Cep290 and Rpe65 (Stasheff et al., 2014). In some animal models, specific intra-retinal synaptic pathways are preferentially altered in the face of others that remain unchanged (Soto and Kerschensteiner, 2015; Tu et al., 2016).

It also has been long recognized that changes in the frequency composition of RGC activity - particularly during select periods of early visual system development - can substantially alter the distribution of RGC axon projections to central visual system targets such as the lateral geniculate nucleus, superior colliculus, and visual cortex (Hanganu et al., 2006; Rebsam et al., 2009; Stafford et al., 2009; Ackman et al., 2012; Burbridge et al., 2014). Thus, variations in specific parameters of RGC hyperactivity among different forms of retinal degeneration may translate to differences in the visual perception of patients with these varied diseases, either directly or by the way they impact downstream processing of visual information in central visual pathways (lateral geniculate, primary, extrastriate, and associational cortices). It should be noted that although RGC spontaneous hyperactivity has been demonstrated consistently by many researchers and in multiple animal models, and abnormal visual percepts described by many patients across a broad variety of retinal diseases, a direct causal relationship between the two remains essentially speculative. Sufficiently sensitive technologic methods are not yet available to detect human RGC hyperactivity reliably or, conversely, to assess conscious visual perceptions of laboratory animals with retinal degeneration.

\section{IMPLICATIONS FOR DIAGNOSIS AND TREATMENT OF RETINAL DEGENERATIONS}

How can further understanding of the spontaneous RGC hyperactivity that accompanies retinal degenerations contribute to improved clinical diagnosis and treatment of these diseases? I have already discussed how the incorporation of specialized but simple psychophysical testing such as low contrast acuity with or without added "noise" (Pelli et al., 2004; McAnany et al., 2013) may improve diagnostic sensitivity, so that these diseases may be detected earlier. Perhaps particular forms of retinal degeneration also may be distinguished at an earlier stage of disease, enabling earlier and more targeted treatment. If proven sufficiently sensitive and specific in the future, such testing might be useful for staging disease, selecting optimal patients for treatment, and/or predicting treatment responsiveness.

To the extent that RGC hyperactivity plays a critical role in establishing retinal and central circuits for visual processing during an early developmental period, its emergence as retinal degenerations progress may help explain the considerably greater effectiveness of treatments such as gene therapy in young children vs. adults (Maguire et al., 2009; Ashtari et al., 2015). Direct modulation of RGC hyperactivity - perhaps as a primary therapy, or as a complementary adjunctive treatment - might improve outcomes and/or delay disease (Toychiev et al., 2013; Barrett et al., 2015, 2016). Cutting-edge treatments such as electrical stimulation via a visual prosthesis (Weiland et al., 2016; Cheng et al., 2017; Mills et al., 2017) may allow very specific modulation of RGC activity so as to counteract excessive "random noise," and/or fine tune the complex signals that encode visual information sent to the brain (Sekirnjak et al., 2008; Freeman et al., 2011; Nirenberg and Pandarinath, 2012; Jepson et al., 2014; Im and Fried, 2015). Finally, to the extent that RGC hyperactivity can be attributed to specific neurotransmitter systems in particular forms of retinal degeneration (Biswas et al., 2014; Liu et al., 2015; Ivanova et al., 2016; Tu et al., 2016), it may be possible to selectively modulate the responsible systems and improve the effective "signal-to-noise ratio" of retinal signaling, and thus improve overall conscious visual perception in these patients.

\section{SUMMARY AND CONCLUSION}

Over the past decade, there has been an acceleration of discoveries revealing that hereditary retinal degenerations involve not only abnormal function of the outer retina (photoreceptors and support cells) but also substantial reorganization of circuitry and electrophysiologic functioning of the inner retina, culminating in abnormal output of RGCs. This includes an increase in background spontaneous activity originating from multiple sites, from the level of photoreceptors, horizontal cells, and bipolar cells to the output level of RGCs. The aberrant activity often is rhythmic and oscillatory and may affect changes in neural connectivity and function in further downstream visual centers of the CNS. 
The discovered background spontaneous hyperactivity of RGCs may help explain the variety of phosphenes and other visual phenomena experienced by many patients in some stages of retinal degeneration. It may also degrade normal visual perception, but alternatively might actually improve perception under certain conditions (e.g., via stochastic resonance). Individual visual processing pathways may be selectively affected, causing specific distortions in visual perception, and even translate to complex visual phenomena - including formed hallucinations - at a cortical level. Because of disruptions in normal developmental maturation of these retinal circuits, early identification and treatment of these disorders may be critical for developing therapies that ultimately are more effective. Finally, basic mechanisms identified to date do suggest some further avenues to explore in order to improve clinical testing of patients, for both diagnosis and the identification of optimal candidates for specific treatments in clinical trials.

There is a great deal yet to be learned about the clinical implications of these findings for patients with retinal degeneration. However, studies of animal models such as those in this Research Topic highlight a variety of key features of this reorganization and suggest previously unrecognized mechanisms

\section{REFERENCES}

Ackman, J. B., Burbridge, T. J., and Crair, M. C. (2012). Retinal waves coordinate patterned activity throughout the developing visual system. Nature 490, 219-225. doi: 10.1038/nature11529

Ashtari, M., Cyckowski, L., Yazdi, A., Viands, A., Marshall, K., Bókkon, I., et al. (2014). fMRI of retina-originated phosphenes experienced by patients with leber congenital amaurosis. PLoS One 9:e86068. doi: 10.1371/journal.pone. 0086068

Ashtari, M., Zhang, H., Cook, P. A., Cyckowski, L. L., Shindler, K. S., Marshall, K. A., et al. (2015). Plasticity of the human visual system after retinal gene therapy in patients with Leber's congenital amaurosis. Sci. Transl. Med. 7:296ra110. doi: 10.1126/scitranslmed.aaa8791

Baccus, S. A. (2007). Timing and computation in inner retinal circuitry. Annu. Rev. Physiol. 69, 271-290. doi: 10.1146/annurev.physiol.69.120205.124451

Barrett, J., Degenaar, P., and Sernagor, E. (2015). Blockade of pathological retinal ganglion cell hyperactivity improves optogenetically evoked light responses in rd1 mice. Front. Cell. Neurosci. 9:330 doi: 10.3389/fncel.2015.00330

Barrett, J. M., Hilgen, G., and Sernagor, E. (2016). Dampening spontaneous activity improves the light sensitivity and spatial acuity of optogenetic retinal prosthetic responses. Sci. Rep. 6:33565. doi: 10.1038/srep33565

Biswas, S., Haselier, C., Mataruga, A., Thumann, G., Walter, P., and Muller, F. (2014). Pharmacological analysis of intrinsic neuronal oscillations in rd10 retina. PLoS One 9:e99075. doi: 10.1371/journal.pone.0099075

Bittner, A. K., Diener-West, M., and Dagnelie, G. (2009). A survey of photopsias in self-reported retinitis pigmentosa: location of photopsias is related to disease severity. Retina 29, 1513-1521. doi: 10.1097/IAE.0b013e3181af0d57

Bittner, A. K., Diener-West, M., and Dagnelie, G. (2011). Characteristics and possible visual consequences of photopsias as vision measures are reduced in retinitis pigmentosa. Invest. Ophthalmol. Vis. Sci. 52, 6370-6376. doi: 10.1167/ iovs.11-7195

Brown, G. C., Brown, M. M., and Fischer, D. H. (2015). Photopsias: a key to diagnosis. Ophthalmology 122, 2084-2094. doi: 10.1016/j.ophtha.2015.06.025

Burbridge, T. J., Xu, H. P., Ackman, J. B., Ge, X., Zhang, Y., Ye, M. J., et al. (2014). Visual circuit development requires patterned activity mediated by retinal acetylcholine receptors. Neuron 84, 1049-1064. doi: 10.1016/j.neuron. 2014.10.051 that may explain patients' symptoms. Because certain of these characteristics appear to be disease-specific, they also may help to diagnose specific disorders earlier and more accurately. For example, current clinical tests such as low-contrast visual acuity charts may be adapted to assess for intrinsic "equivalent noise" and potentially quantify disease stage, perhaps even predict treatment responses in individual patients. Ultimately, deeper understanding of the inner retina's reorganization may pave the road to more mechanistically targeted therapies and provide more specific tests to screen for optimal subjects in clinical trials of new and evolving treatments.

\section{AUTHOR CONTRIBUTIONS}

SS reviewed relevant literature, wrote and revised the manuscript, read and approved the submitted version.

\section{FUNDING}

SS was funded in part by the Gilbert Family Neurofibromatosis Institute.

Cammaroto, S., D'aleo, G., Smorto, C., and Bramanti, P. (2008). Charles bonnet syndrome. Funct. Neurol. 23, 123-127.

Chaisanguanthum, K. S., Joshua, M., Medina, J. F., Bialek, W., and Lisberger, S. G. (2014). The neural code for motor control in the cerebellum and oculomotor Brainstem. eNeuro 1:e0004-14.2014, 1-17. doi: 10.1523/ENEURO. 0004-14.2014

Cheng, D. L., Greenberg, P. B., and Borton, D. A. (2017). Advances in retinal prosthetic research: a systematic review of engineering and clinical characteristics of current prosthetic initiatives. Curr. Eye. Res 42, 334-347. doi: 10.1080/02713683.2016.1270326

Crair, M. C., and Mason, C. A. (2016). Reconnecting eye to brain. J. Neurosci. 36, 10707-10722. doi: 10.1523/JNEUROSCI.1711-16.2016

Dräger, U. C., and Hubel, D. H. (1978). Studies of visual function and its decay in mice with hereditary retinal degeneration. J. Comp. Neurol. 180, 85-114. doi: $10.1002 / \mathrm{cne} .901800107$

Euler, T., and Schubert, T. (2015). Multiple independent oscillatory networks in the degenerating retina. Front. Cell. Neurosci. 9:444. doi: 10.3389/fncel.2015.00444

Ffytche, D. H. (2005). Visual hallucinations and the Charles Bonnet syndrome. Curr. Psychiatry Rep. 7, 168-179. doi: 10.1007/s11920-005-0050-3

Ffytche, D. H. (2009). Visual hallucinations in eye disease. Curr. Opin. Neurol 22, 28-35. doi: 10.1097/WCO.0b013e32831f1b3f

Field, G. D., and Chichilnisky, E. J. (2007). Information processing in the primate retina: circuitry and coding. Annu. Rev. Neurosci. 30, 1-30. doi: 10.1146/ annurev.neuro.30.051606.094252

Fisher, R. S. (2017). An overview of the 2017 ILAE operational classification of seizure types. Epilepsy Behav. 70, 271-273. doi: 10.1016/j.yebeh.2017.03.022

Fisher, R. S., Cross, J. H., French, J. A., Higurashi, N., Hirsch, E., Jansen, F. E., et al. (2017). Operational classification of seizure types by the international league against epilepsy: position paper of the ILAE commission for classification and terminology. Epilepsia 58, 522-530. doi: 10.1111/epi.13670

Freeman, D. K., Rizzo, J. F., and Fried, S. I. (2011). Encoding visual information in retinal ganglion cells with prosthetic stimulation. J. Neural Eng. 8:035005. doi: 10.1088/1741-2560/8/3/035005

Funke, K., Kerscher, N. J., and Worgotter, F. (2007). Noise-improved signal detection in cat primary visual cortex via a well-balanced stochastic resonancelike procedure. Eur. J. Neurosci. 26, 1322-1332. doi: 10.1111/j.1460-9568.2007. 05735.x 
Goo, Y. S., Ahn, K. N., Song, Y. J., Ahn, S. H., Han, S. K., Ryu, S. B., et al. (2011a). Spontaneous oscillatory rhythm in retinal activities of two retinal degeneration (rd1 and rd10) Mice. Korean J. Physiol. Pharmacol. 15, 415-422. doi: 10.4196/kjpp.2011.15.6.415

Goo, Y. S., Ahn, K. N., Song, Y. J., Ryu, S. B., and Kim, K. H. (2011b). Comparison of basal oscillatory rhythm of retinal activities in $\mathrm{rd} 1$ and $\mathrm{rd} 10$ mice. Conf. Proc. IEEE Eng. Med. Biol. Soc. 2011, 1093-1096. doi: 10.1109/IEMBS.2011.6090255

Goo, Y. S., Park, D. J., Ahn, J. R., and Senok, S. (2016). Spontaneous oscillatory rhythms in the degenerating mouse retina modulate retinal ganglion cell responses to electrical stimulation. Front. Cell. Neurosci. 9:512. doi: 10.3389/ fncel.2015.00512

Hanganu, I. L., Ben-Ari, Y., and Khazipov, R. (2006). Retinal waves trigger spindle bursts in the neonatal rat visual cortex. J. Neurosci. 26, 6728-6736. doi: 10.1523/ JNEUROSCI.0752-06.2006

Heckenlively, J. R., Yoser, S. L., Friedman, L. H., and Oversier, J. J. (1988). Clinical findings and common symptoms in retinitis pigmentosa. Am. J. Ophthalmol. 105, 504-511. doi: 10.1016/0002-9394(88)90242-5

Hedges, T. R. Jr. (2007). Charles Bonnet, his life, and his syndrome. Surv. Ophthalmol. 52, 111-114. doi: 10.1016/j.survophthal.2006.10.007

Im, M., and Fried, S. I. (2015). Indirect activation elicits strong correlations between light and electrical responses in ON but not OFF retinal ganglion cells. J. Physiol. 593, 3577-3596. doi: 10.1113/JP270606

Ioffe, M. L., and Berry, M. J., 2nd. (2017). The structured' low temperature' phase of the retinal population code. PLoS Comput. Biol. 13:e1005792. doi: 10.1371/ journal.pcbi.1005792

Ivanova, E., Yee, C. W., Baldoni, R. Jr., and Sagdullaev, B. T. (2015a). Aberrant activity in retinal degeneration impairs central visual processing and relies on Cx36-containing gap junctions. Exp. Eye Res. 150, 81-99. doi: 10.1016/j.exer. 2015.05.013

Ivanova, E., Yee, C. W., and Sagdullaev, B. T. (2015b). Increased phosphorylation of Cx36 gap junctions in the AII amacrine cells of RD retina. Front. Cell. Neurosci. 9:390. doi: $10.3389 /$ fncel. 2015.00390

Ivanova, E., Yee, C. W., and Sagdullaev, B. T. (2016). Disruption in dopaminergic innervation during photoreceptor degeneration. J. Comp. Neurol. 524, 1208-1221. doi: 10.1002/cne.23899

Jacobs, A. L., Fridman, G., Douglas, R. M., Alam, N. M., Latham, P. E., Prusky, G. T., et al. (2009). Ruling out and ruling in neural codes. Proc. Natl. Acad. Sci. U.S.A. 106, 5936-5941. doi: 10.1073/pnas.0900573106

Jepson, L. H., Hottowy, P., Mathieson, K., Gunning, D. E., Dabrowski, W., Litke, A. M., et al. (2014). Spatially patterned electrical stimulation to enhance resolution of retinal prostheses. J. Neurosci. 34, 4871-4881. doi: 10.1523/ JNEUROSCI.2882-13.2014

Kim, Y. J., Grabowecky, M., and Suzuki, S. (2006). Stochastic resonance in binocular rivalry. Vision Res. 46, 392-406. doi: 10.1016/j.visres.2005.08.009

Koepsell, K., Wang, X., Vaingankar, V., Wei, Y., Wang, Q., Rathbun, D. L., et al. (2009). Retinal oscillations carry visual information to cortex. Front. Syst. Neurosci. 3:4. doi: 10.3389/neuro.06.004.2009

Liu, X., Zhang, Y., He, Y., Zhao, J., and Su, G. (2015). Progress in histopathologic and pathogenetic research in a retinitis pigmentosa model. Histol. Histopathol. $30,771-779$.

Luo, Y., and Anderson, T. A. (2016). Phantom limb pain: a review. Int. Anesthesiol. Clin. 54, 121-139. doi: 10.1097/AIA.0000000000000095

Maguire, A. M., High, K. A., Auricchio, A., Wright, J. F., Pierce, E. A., Testa, F., et al. (2009). Age-dependent effects of RPE65 gene therapy for Leber's congenital amaurosis: a phase 1 dose-escalation trial. Lancet 374, 1597-1605. doi: 10.1016/ S0140-6736(09)61836-5

Margolis, D. J., and Detwiler, P. B. (2011). Cellular origin of spontaneous ganglion cell spike activity in animal models of retinitis pigmentosa. J. Ophthalmol. 2011: 507037. doi: 10.1155/2011/507037

Marre, O., Botella-Soler, V., Simmons, K. D., Mora, T., Tkačik, G., Berry, M. J., et al. (2015). High accuracy decoding of dynamical motion from a large retinal population. PLoS Comp. Biol. 11:e1004304. doi: 10.1371/journal.pcbi.10 04304

McAnany, J. J., Alexander, K. R., Genead, M. A., and Fishman, G. A. (2013). Equivalent intrinsic noise, sampling efficiency, and contrast sensitivity in patients with retinitis pigmentosa. Invest. Ophthalmol. Vis. Sci. 54, 3857-3862. doi: $10.1167 /$ iovs.13-11789
Menzler, J., Channappa, L., and Zeck, G. (2014). Rhythmic ganglion cell activity in bleached and blind adult mouse retinas. PLoS One 9:e106047. doi: 10.1371/ journal.pone. 0106047

Menzler, J., and Zeck, G. (2011). Network oscillations in rod-degenerated mouse retinas. J. Neurosci. 31, 2280-2291. doi: 10.1523/JNEUROSCI.4238-10.2011

Mills, J. O., Jalil, A., and Stanga, P. E. (2017). Electronic retinal implants and artificial vision: journey and present. Eye 31, 1383. doi: 10.1038/eye.2017.65

Murtha, T., and Stasheff, S. F. (2003). Visual dysfunction in retinal and optic nerve disease. Neurol. Clin. 21, 445-481. doi: 10.1016/S0733-8619(02)00108-1

Nirenberg, S., and Pandarinath, C. (2012). Retinal prosthetic strategy with the capacity to restore normal vision. Proc. Natl. Acad. Sci. U.S.A. 109, 15012-15017. doi: 10.1073/pnas.1207035109

Pang, L. (2016). Hallucinations experienced by visually impaired: charles bonnet syndrome. Optom. Vis. Sci. 93, 1466-1478. doi: 10.1097/OPX. 0000000000000959

Patel, A., and Kosko, B. (2005). Stochastic resonance in noisy spiking retinal and sensory neuron models. Neural Netw. 18, 467-478. doi: 10.1016/j.neunet.2005. 06.031

Pelli, D. G., Levi, D. M., and Chung, S. T. (2004). Using visual noise to characterize amblyopic letter identification. J. Vis. 4, 904-920. doi: 10.1167/4.10.6

Pirowska, A., Wloch, T., Nowobilski, R., Plaszewski, M., Hocini, A., and Ménager, D. (2014). Phantom phenomena and body scheme after limb amputation: a literature review. Neurol. Neurochir. Pol. 48, 52-59. doi: 10.1016/ j.pjnns.2013.03.002

Rachmachandran, V. S. (1992). Filling in gaps in perception: part II. Scotomas and phantom limbs. Curr. Dir. Psychol. Sci. 2, 56-65. doi: 10.1111/1467-8721. ep10770702

Rebsam, A., Petros, T. J., and Mason, C. A. (2009). Switching retinogeniculate axon laterality leads to normal targeting but abnormal eye-specific segregation that is activity dependent. J. Neurosci. 29, 14855-14863. doi: 10.1523/JNEUROSCI. 3462-09.2009

Rucci, M., and Victor, J. D. (2015). The unsteady eye: an information-processing stage, not a bug. Trends Neurosci 38, 195-206. doi: 10.1016/j.tins.2015.01.005

Ryu, S. B., Ye, J. H., Goo, Y. S., Kim, C. H., and Kim, K. H. (2010). Temporal Response Properties of Retinal Ganglion Cells in rd1 Mice Evoked by Amplitude-Modulated Electrical Pulse Trains. Invest. Ophthalmol. Vis. Sci. 51, 6762-6769. doi: 10.1167/iovs.10-5577

Schadlu, A. P., Schadlu, R., and Shepherd, J. B. 3rd. (2009). Charles Bonnet syndrome: a review. Curr. Opin. Ophthalmol 20, 219-222. doi: 10.1097/ICU. 0b013e328329b643

Schwartz, G., and Berry, M. J. 2nd. (2008). Sophisticated temporal pattern recognition in retinal ganglion cells. J. Neurophysiol. 99, 1787-1798. doi: 10.1152/jn.01025.2007

Sekirnjak, C., Hottowy, P., Sher, A., Dabrowski, W., Litke, A. M., and Chichilnisky, E. J. (2008). High-resolution electrical stimulation of primate retina for epiretinal implant design. J. Neurosci 28, 4446-4456. doi: 10.1523/JNEUROSCI. 5138-07.2008

Shannon, C. E. (1948). A mathematical theory of communication. Bell Syst. Tech. J. 27, 379-423. doi: 10.1002/j.1538-7305.1948.tb01338.x

Sincich, L. C., Horton, J. C., and Sharpee, T. O. (2009a). Preserving information in neural transmission. J. Neurosci. 29, 6207-6216. doi: 10.1523/JNEUROSCI. 3701-08.2009

Sincich, L. C., Zhang, Y., Tiruveedhula, P., Horton, J. C., and Roorda, A. (2009b). Resolving single cone inputs to visual receptive fields. Nat. Neurosci. 12, 967-969. doi: 10.1038/nn.2352

Soto, F., and Kerschensteiner, D. (2015). Synaptic remodeling of neuronal circuits in early retinal degeneration. Front. Cell. Neurosci. 9:395. doi: 10.3389/fncel. 2015.00395

Soto, F., Ma, X., Cecil, J. L., Vo, B. Q., Culican, S. M., and Kerschensteiner, D. (2012). Spontaneous activity promotes synapse formation in a cell-typedependent manner in the developing retina. J. Neurosci. 32, 5426-5439. doi: 10.1523/JNEUROSCI.0194-12.2012

Stafford, B. K., Sher, A., Litke, A. M., and Feldheim, D. A. (2009). Spatialtemporal patterns of retinal waves underlying activity-dependent refinement of retinofugal projections. Neuron 64, 200-212. doi: 10.1016/j.neuron.2009.09.021

Stasheff, S. F., Spalding, K. N., Blodi, F. R., Shankar, M., Bhattarai, S., Thompson, S., et al. (2014). Distinct profiles of abnormal ganglion cell activity in two 
forms of Leber's congenital amaurosis (LCA): implications for therapy. Invest. Ophthalmol. Vis. Sci. 55, 357-357.

Tkacik, G., Prentice, J. S., Balasubramanian, V., and Schneidman, E. (2010). Optimal population coding by noisy spiking neurons. Proc. Natl. Acad. Sci. U.S.A. 107, 14419-14424. doi: 10.1073/pnas.100490 6107

Toychiev, A. H., Ivanova, E., Yee, C. W., and Sagdullaev, B. T. (2013). Block of gap junctions eliminates aberrant activity and restores light responses during retinal degeneration. J. Neurosci. 33, 13972-13977. doi: 10.1523/JNEUROSCI.2399-13. 2013

Trenholm, S., and Awatramani, G. B. (2015). Origins of spontaneous activity in the degenerating retina. Front. Cell. Neurosci. 9:277. doi: 10.3389/fncel.2015. 00277

Trevino, M., De La Torre-Valdovinos, B., and Manjarrez, E. (2016). Noise improves visual motion discrimination via a stochastic resonance-like phenomenon. Front. Hum. Neurosci. 10:572. doi: 10.3389/fnhum.2016.00572

Tu, H. -Y., Chen, Y. -J., Mcquiston, A. R., Chiao, C. -C., and Chen, C. -K. (2016). A novel retinal oscillation mechanism in an autosomal dominant photoreceptor degeneration mouse model. Front. Cell. Neurosci. 9:513. doi: 10.3389/fncel. 2015.00513

van der Groen, O., and Wenderoth, N. (2016). Transcranial random noise stimulation of visual cortex: stochastic resonance enhances central mechanisms of perception. J. Neurosci. 36, 5289-5298. doi: 10.1523/JNEUROSCI.4519-15. 2016

Wang, Y., Chen, K., Xu, P., Ng, T. K., and Chan, L. L. H. (2016). Spontaneous neural activity in the primary visual cortex of retinal degenerated rats. Neurosci. Lett. 623, 42-46. doi: 10.1016/j.neulet.2016.04.062
Weiland, J. D., Walston, S. T., and Humayun, M. S. (2016). Electrical Stimulation of the Retina to Produce Artificial Vision. Annu. Rev. Vis. Sci. 2, 273-294. doi: 10.1146/annurev-vision-111815-114425

Wu, W., and Srivastava, A. (2011). An information-geometric framework for statistical inferences in the neural spike train space. J. Comput. Neurosci. 31, 725-748. doi: 10.1007/s10827-011-0336-x

Xiao, L., Zhang, M., Xing, D., Liang, P. J., and Wu, S. (2013). Shifted encoding strategy in retinal luminance adaptation: from firing rate to neural correlation. J. Neurophysiol. 110, 1793-1803. doi: 10.1152/jn.00221. 2013

Yee, C. W., Toychiev, A. H., Ivanova, E., and Sagdullaev, B. T. (2014). Aberrant synaptic input to retinal ganglion cells varies with morphology in a mouse model of retinal degeneration. J. Comp. Neurol. 522, 4085-4099. doi: 10.1002/ cne. 23660

Zeck, G. (2016). Aberrant activity in degenerated retinas revealed by electrical imaging. Front. Cell. Neurosci. 10:25. doi: 10.3389/fncel.2016.00025

Conflict of Interest Statement: The author declares that the research was conducted in the absence of any commercial or financial relationships that could be construed as a potential conflict of interest.

Copyright (c) 2018 Stasheff. This is an open-access article distributed under the terms of the Creative Commons Attribution License (CC BY). The use, distribution or reproduction in other forums is permitted, provided the original author(s) and the copyright owner(s) are credited and that the original publication in this journal is cited, in accordance with accepted academic practice. No use, distribution or reproduction is permitted which does not comply with these terms. 